\title{
Assisted reproduction and genetics
}

European Journal of Human Genetics (2006) 14, 505. doi:10.1038/sj.ejhg.5201609

Infertility is regarded as a growing health problem and, in spite of the fact that many of its causes are societal, medical approaches in the form of different assisted reproductive techniques are widely used to solve this problem. Some aspects of these treatments have generally been found problematic, like the moral status of an embryo and its rights, accepting single females and female couples as clients of fertility clinics, and the use of anonymous donors of germ cells or embryos. These problematic questions have led to astonishingly different regulative solutions in the European member states: while some countries have rather permissive laws, others limit access to IVF services very narrowly.

The many genetic issues related to assisted reproduction have been less prominently discussed even though there are several unanswered questions in the overlapping area of the two disciplines infertility treatment and genetics.

How carefully should the possible genetic cause of the infertility be examined? Should the possible, albeit rare genetic risks always be discussed with the couple even though it might increase their concerns? Like, for instance, the risk that an azoospermic man turns out to be a carrier of a severe CF mutation and also happens to have another carrier as his spouse? Should the donors be tested for carriership of some conditions in a population where there are no carrier screening programs for normally fertile couples? Should the apparently very rare risks, like risk of imprinting errors, be explained to all couples considering assisted reproduction or preimplantation diagnostics?
Which indications justify preimplantation genetic diagnosis? And what is the goal of preimplantation genetic screening: is it performed only to improve the pregnancy rates or are there some eugenic goals as well?

The Public and Professional Policy Committee (PPPC) of ESHG came to the conclusion that time had come to discuss these issues to create professional recommendations on how to use IVF techniques safely and reliably from the genetic point of view. PPPC joined its forces with the European Society of Human Reproduction and Embryology (ESHRE) and the Institute for Prospective Technological studies (IPTS) of EU to discuss the topic further. After having circulated the background document to more than 100 experts for comments, they organised a Workshop in Seville on March 31-1 April 2005. The discussion led to consensus about professional recommendations between the ESHG and the ESHRE, which EJHG is pleased to present to its readers in this issue along with the full background document. ${ }^{1,2}$

\section{References}

1 The need for interaction between assisted reproduction technology and genetics. Eur J Hum Genet 2006; 14: 509-511.

2 Soini S, Ibarreta D, Anastasiadou et al on behalf of ESHG and ESHRE: The interface between assisted reproductive technologies and genetics: technical, social, ethical and legal issues. Eur J Hum Genet 2006; 14: 588-645.

Helena Kääriäinen Turku Finland, Guest Editor ART and Genetics 